\title{
nejpec
}

\section{Pequena produção leiteira no sul do Maranhão: Instruções normativas oficiais e adequação dos produtores}

\section{Cesar Augustus Labre Lemos de Freitas}

Prof. do Programa de Pós-Graduação em Desenvolvimento Socioeconômico e do Dept. de Economia da UFMA

Email: cesarlabre@bol.com.br

\section{João Gonsalo de Moura}

Prof. do Programa de Pós-Graduação em Desenvolvimento Socioeconômico e do Dept. de Economia da UFMA

Email: jgmoura1964@gmail.com

\section{Ricardo Zimbrão Affonso de Paula}

Prof. do Programa de Pós-Graduação em Desenvolvimento Socioeconômico e do Dept. de Economia da UFMA

Email: ricardo.zimbrao@gmail.com

Resumo: Diante da vasta gama de atividades que compõem o agronegócio, a pecuária de leite assume um papel de destaque e dada a pequena capacidade de mobilização de recursos por parte dos pequenos pecuaristas instalados em regiões menos abastadas, como é o caso da microrregião de Imperatriz, na região Sul do Maranhão, é possível que centenas de estabelecimentos tenham o seu funcionamento inviabilizado, considerando a baixa adesão dos pecuaristas às normas estabelecidas. O objetivo do presente trabalho é analisar os fatores determinantes da adesão das propriedades leiteiras da mencionada região aos padrões normativos oficiais.

Palavras chaves: Pecuária de leite; Agronegócio; Políticas Públicas.

\begin{abstract}
Given the wide range of activities that make up agribusiness, dairy farming plays an important role and given the small capacity of resource mobilization by small farmers located in less wealthy regions, such as the micro-region of Imperatriz, in the In the southern region of Maranhão, it is possible that hundreds of establishments have been rendered unfeasible, considering the low adherence of cattle ranchers to established standards. The objective of the present work is to analyze the factors determining the adhesion of dairy farms in the region to official standards.
\end{abstract}

Key words: Dairy cattle; Agribusiness; Public policy. 
p. 3 - Pequena produção leiteira no sul do Maranhão: Instruções normativas oficiais e adequação dos produtores

\section{INTRODUÇÃO}

Até mesmo pela disponibilidade de terras em abundância e condições propícias, o Brasil tem se consolidado como um grande produtor de leite e derivados, aparecendo entre os seis maiores produtores mundiais. Entretanto, em termos de eficiência, porém, os indicadores brasileiros deixam muito a desejar, exibindo um cenário de baixa produtividade e custos elevados, quando são tomados como referência os padrões encontrados nos países que se encontram no topo da lista. Isto inibe sobremaneira os níveis de ocupação e renda proporcionados pela atividade, bem como a sua própria contribuição para superar os níveis de pobreza e desigualdade prevalecentes no meio rural brasileiro (RESENDE, 2006).

As causas para a ineficiência da produção de leite em algumas regiões do país pode ser especulada a partir de aspectos como o fato de alguns produtores estarem ligados à atividade muito mais por mera tradição familiar do que propriamente pela necessidade de alcance de alguma meta de retorno econômico; ou mesmo devido ao fato de produzirem para atender mercados informais, atuando fora dos padrões de exigência impostos pelos mercados organizados. Em alguns casos, esta configuração pode ser explicada pelo fato de algumas dessas exigências serem incompatíveis com o tamanho e a capacidade de mobilização de recursos por parte dos produtores, que em geral são de pequeno porte.

Ao longo dos últimos anos, mesmo que a passos não tão largos, a cadeia produtiva do leite no Brasil tem passado por um conjunto de adaptações e mudanças importantes, provocadas, sobretudo, pela regulamentação oficial do setor. Na tentativa de adequar a produção brasileira aos melhores padrões mundiais, um conjunto de instruções normativas oriundas do Ministério da Agricultura tem provocado ajustes no modo como o produto é produzido, armazenado, transportado, comercializado, etc.

Em meio a este cenário termina ocorrendo uma espécie de seleção natural dos estabelecimentos, tendo em vista que nem todos conseguem se adequar ao contexto, por razões que são as mais diversas, como a capacidade de mobilização de recursos para tal, ou mesmo pelos próprios propósitos dos pecuaristas. No entanto, tal seleção se estabelece no sentido de proporcionar aos produtores que conseguem se adaptar o acesso a mercados organizados, enquanto aqueles que não se adaptam passam a operar apenas em uma fração marginal do mercado leiteiro, caracterizada, principalmente, pela baixa organização, ou mesmo informalidade gerando assim uma espécie de dualidade na atividade.

Em ambientes mais específicos, como na microrregião de Imperatriz, no Sul do Maranhão, quando os estabelecimentos leiteiros, geralmente de pequeno porte, são confrontados com as crescentes exigências em termos de métodos, qualidade e padrões de eficiência na produção, talvez pelos motivos anteriormente expostos, tendem a conviver com um maior nível de inclinação à mera subsistência e à atuação em faixas marginais do mercado, pois, como será visto ao longo deste trabalho, grande parte dos estabelecimentos leiteiros não parece estar em condições de enquadramento imediato às exigências impostas pelo mercado e/ou pelos órgãos oficiais regulamentadores (MOREIRA, 2016). 
Instruções Normativas como as de № 51 e de № 62 (IN № 51 e IN № 62) do Ministério da Agricultura, que deveriam despertar os produtores para a implantação de melhorias em suas propriedades, parecem não vir cumprindo o seu objetivo final, tendo em vista que apenas um grupo reduzido de propriedades adotou as providências cabíveis para atender aos padrões exigidos naqueles instrumentos normativos (MOREIRA, 2016; SEBRAE, 2016).

Deste modo, o objetivo principal do presente trabalho é examinar as causas que induzem um grupo de produtores a tomar providências para se adaptar aos instrumentos normativos, enquanto outro grupo não o faz, buscando identificar algumas características que diferenciem tais grupos de estabelecimentos da pecuária de leite. Para alcançar o referido objetivo, será utilizado como base um conjunto de dados produzidos através de uma pesquisa de campo realizada em dezembro de 2015, decorrente de Convênio entre a Universidade Federal do Maranhão (UFMA) e o Serviço Brasileiro de Apoio às Micro e Pequenas empresas (SEBRAE-MA) e, sobre este conjunto de dados, será aplicado um modelo binário de estimação (modelo Logit), de forma que possam emergir evidências sobre os elementos que afetam as decisões dos pecuaristas quanto à adaptação aos padrões normativos do setor.

O presente trabalho se encontra organizado em cinco seções, iniciando-se por esta introdução. Na seção seguinte foi desenvolvido um breve histórico do setor no Brasil e do papel do Estado enquanto regulamentador da produção e da comercialização do produto. A terceira seção foi dedicada a uma breve descrição do perfil dos produtores de leite da microrregião de Imperatriz, na tentativa de subsidiar a posterior interpretação das estimativas resultantes da aplicação da metodologia proposta. A quarta seção ficou estruturada em dois temas: o primeiro foi a apresentação da metodologia do trabalho; enquanto o segundo foi destinado à análise dos resultados que emergiram do emprego da metodologia. Por fim, na quinta seção foram expostas as considerações finais.

\section{2. CARACTERIZAÇÃO DA ATIVIDADE}

Tendo em vista esta dimensão econômica e social da atividade leiteira, em diferentes países a presença do Estado no setor tende a assumir propósitos distintos. Em alguns casos, como é mais marcante no Brasil desde os anos 1990, o papel do Estado visa muito mais aproximar o setor dos parâmetros de uma economia de mercado, exigindo dos produtores o cumprimento de normas que garantam a qualidade do produto e a segurança dos consumidores (MEIRELES, 1996).

Em outros países, sobretudo no continente europeu, o papel do Estado se manifesta muito mais no sentido de conceder medidas protecionistas ao produto originário do mercado interno, atuando por meio da concessão de incentivos e subsídios. Ou seja, as políticas direcionadas ao setor leiteiro em regiões mais desenvolvidas visam potencializara renda da atividade leiteira doméstica, por meio de reserva de mercado e incrementos artificiais nas remunerações recebidas pelos produtores, ao contrário de países como o Brasil onde a ausência de tais mecanismos de proteção visa tornar a atividade mais eficiente, além de buscar aperfeiçoamentos qualitativos que promovam maiores níveis de sanidade e qualidade ao produto (ARÊDES et al, 2006; SEBRAE, 2003). 
p. 5 - Pequena produção leiteira no sul do Maranhão: Instruções normativas oficiais e adequação dos produtores

No exercício do seu direito de elaborar políticas voltadas para o setor, os países podem fazê-lo por meio do uso de mecanismos distintos, quais sejam: i) criação e manutenção de órgãos que tenham por finalidade regulamentar e fiscalizaras atividades que integram a cadeia produtiva, estabelecendo normas e padrões de qualidade; ii) adoção de medidas que visem a proteção à produção interna através do uso de mecanismos como compra do produto, estabelecimento de preços mínimos, oferta de subsídios à atividade, de forma que a renda dos produtores sofra menos oscilações e se torne mais previsível; iii) adoção de medidas restritivas às importações e/ou medidas de estímulo às exportações, garantindo que o setor não seja exposto à concorrência do produto importado, ou mesmo que tenha acesso privilegiado ao mercado externo. 0 primeiro caso retrata com maior aproximação o padrão típico de uma economia de mercado, enquanto os dois últimos retratam mais acuradamente o ambiente típico de uma economia identificada com o protecionismo (WILKINSON, 1993).

Contudo, o caso brasileiro conta com algumas particularidades, pois, como se trata de um setor caracterizado por uma quantidade expressiva de produtores, dispersos por quase toda a extensão do território nacional, e cujo tamanho das unidades produtivas difere substancialmente, torna-se natural que a adaptação a normas e padrões pelas unidades produtivas assumam intensidades e prazos bastante dispersos. É possível encontrar propriedades que produzem leite atendendo aos melhores padrões de excelência, em termos de qualidade e tecnologia, como também é possível encontrar propriedades cujos métodos empregados em nada diferem daqueles que já eram adotados há mais de um século. E isto não se deve exatamente à dimensão territorial brasileira, uma vez que estes dois tipos de estabelecimentos (contrastes) podem estar localizados a poucos km de distância um do outro.

Portanto, identificar alguns dos fatores que explicam esta heterogeneidade na função de reação dos produtores representa um dos principais desafios propostos neste trabalho, especificamente quando se trata dos estabelecimentos sediados na região Sul do Maranhão e, mais especificamente, na microrregião de Imperatriz. As decisões dos produtores neste contexto terminam por viabilizar, ou inviabilizar, a possibilidade de acessar mercados organizados, como seria o caso de importantes compradores, como é o caso dos laticínios (BELIK, 1999).

Diante da própria forma de atuação recente do Estado brasileiro no setor em tela, este estudo se atém à sua presença como provedor dos padrões normativos que disciplinam questões como produção, armazenagem, transporte e comercialização do leite. No entanto, embora seja esta a forma de atuação que tem caracterizado a a presença do setor público a partir dos anos 1990s, torna-se conveniente enfatizar que desde os meados do Século XX, mais precisamente, no início da década 1950, através do Decreto 30.691, o governo brasileiro inaugura a sua atuação no campo normativo da atividade em tela, estabelecendo a criação do Regulamento de Inspeção Industrial e Sanitária de Produtos de Origem Animal (RIISPOA).Esta norma tornava obrigatória uma série de procedimentos na produção e comercialização do leite, como é o caso da pasteurização e da necessidade do carimbo do Serviço de Inspeção Federal (SIF) nos produtos oriundos dos estabelecimentos envolvidos com o comércio interestadual ou internacional do produto (MAIAet al, 2013; BRASIL, 1952). 
Com a criação do Mercado Comum do Sul (MERCOSUL), em 1991, vários ajustes na legislação brasileira de produção e comercialização de produtos de origem animal passam a ser necessários, tendo em vista a necessidade de superação de entraves relacionados às diferenças normativas então prevalecentes nos países signatários do acordo (Brasil, Argentina, Uruguai e Paraguai). Mais especificamente, neste novo ambiente foi expedido um conjunto de normas mais rigorosas para etapas da cadeia produtiva do setor, tais como: transporte, conservação/resfriamento, higiene, pasteurização, dentre outras. Mas não era apenas motivado pelo ingresso no MERCOSUL que o governo brasileiro visava adequar o setor com o estabelecimento de novos padrões normativos. Em última instância, a finalidade principal estava voltada para a segurança do consumidor e a para a própria adequação dos empreendimentos internos aos procedimentos dos principais países produtores, tendo em vista o crescente nível de globalização das economias. (BRASIL, 1996; VIDOR, 2002; MAIA et al, 2013).

Talvez o ponto culminante de todo esse aperfeiçoamento da atividade leiteira via regulamentação oficial, abrangendo praticamente todas as etapas dos processos de produção e comercialização, aconteceu com a edição da Instrução Normativa n 51 (IN 51), de setembro de 2002. Daí resulta uma espécie de resumo de todo o processo normativo das atividades do setor lácteo brasileiro. Tal instrumento normativo visava atingir as suas principais metas em um espaçamento temporal que previa a inclusão de quatro etapas, além de uma diferenciação de tais etapas de acordo com as grandes regiões do país. As normas estipuladas no referido documento deveriam começar a ser observadas a partir 01/07/2002; devendo estar definitivamente consolidadas desde 01/07/2011 nas regiões Sul, Sudeste e Centro-Oeste, e desde 01/07/2012 nas regiões Nordeste e Norte. Tratava-se, portanto de um conjunto de requisitos que abrangiam desde a sanidade do rebanho até o processo de resfriamento do produto, passando pela própria qualidade e adequação do mesmo através da realização de um conjunto de testes e aferições de natureza técnica (BRASIL, 2002; FAGUNDES, 2005).

Antes mesmo do vencimento dos prazos finais estipulados na IN 51 o governo brasileiro constatou que o setor lácteo nacional não conseguiria dar conta de todas as exigências contidas naquele instrumento normativo. Embora grande parte dos produtores já tivesse alcançado os padrões requeridos, uma parcela significativa dos mesmos se encontrava em estágios muito abaixo daqueles previstos pelo calendário de adaptação. Assim, o Ministério da Agricultura emitiu a Instrução Normativa № 62 de dezembro de 2011 (IN 62) que, em linhas gerais, repetia o conteúdo técnico da IN 51, se atendo mais especificamente a mudanças nos prazos de adequação que, dependendo do quesito, passaram a variar desde 01/01/2012 até 01/07/2016 (BRASIL, 2011).

Para não relatar uma completa ausência de novidade em relação à IN 51, faz-se necessário dizer que a IN 62 instituiu uma Comissão Técnica Consultiva encarregada fazer avaliações sobre os resultados das ações voltadas para a melhoria da qualidade do leite produzido no Brasil. Contudo, mesmo repetindo quase a totalidade do conteúdo da norma anterior (IN 51), torna-se importante ressaltar, desde a edição da IN 62, passou a ser este o documento oficial que rege a produção leiteira brasileira. A adaptação de todas as unidades produtivas aos padrões ali estabelecidos passou a representar umacondição 
p. 7 - Pequena produção leiteira no sul do Maranhão: Instruções normativas oficiais e adequação dos produtores

indispensável para que as mesmas pudessem acessar os mercados organizados e continuar comercializando normalmente o leite produzido.

\section{CARACTERIZAÇÃO DO PÚBLICO-ALVO}

As unidades produtoras de leite estabelecidas na região Sul do Maranhão, seguindo a tendência da própria economia maranhense no cenário nacional, apresenta indicadores de eficiência bem abaixo dos padrões observadosem estados brasileiros mais desenvolvidos. Um exemplo bem elucidativo desta proposição pode ser encontrado através da análise dos dados contidos no Gráfico 01, onde consta a participação do estado do Maranhão em alguns indicadores brasileiros, atestando ali a baixa eficiência local.

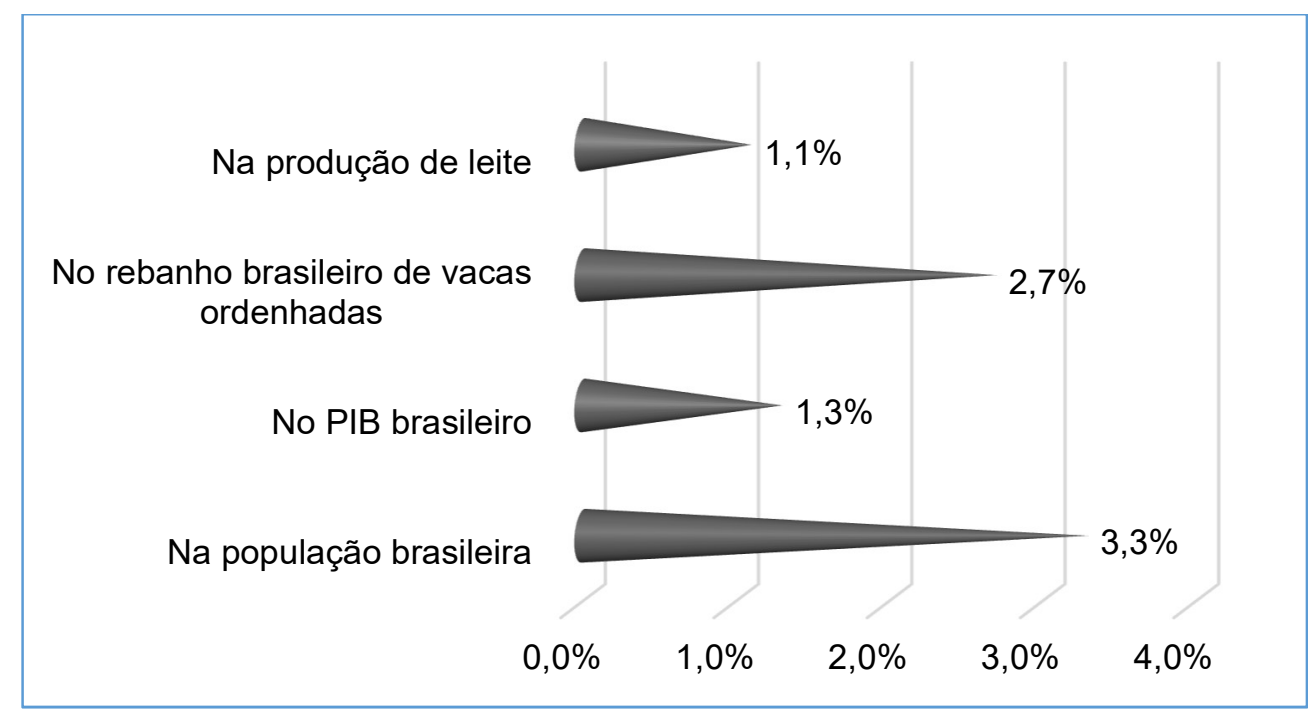

Gráfico 01: Participação do Maranhão em indicadores brasileiros (\% em 2014).

Fonte: IBGE (Banco de dados SIDRA)

Portanto, os dados apresentados no Gráfico 01 atestam a baixa eficiência maranhense. Esta característica aparece no PIB estadual e no caso específico da produção de leite. Na parte superior do referido gráfico pode ser obtida a constatação de que os melhores métodos e processos não são empregados em terras maranhenses, tendo em vista o fato de que, detendo $2,7 \%$ do rebanho nacional de vacas ordenhadas, o estado consegue produzir apenas $1,1 \%$ do quantum nacional de leite. Estes números estão em perfeita sintonia com os demais indicadores ali contidos. Basta observar que 3,3\% da população brasileira, abrigada no território maranhense, consegue contribuir com tão somente $1,3 \%$ da produção nacional de bens e serviços. Ou seja, a ineficiência das propriedades leiteiras reflete as próprias ineficiências presentes na atividade econômica como um todo.

Como este trabalho trata com propriedades produtoras de leite na região Sul do Maranhão e, mais especificamente, na microrregião de Imperatriz, torna-se conveniente fornecer alguns indícios de como os indicadores expostos se comportariam naquela 
fração do estado. Para tanto, o Gráfico 02 expõe um conjunto de dados que permitem a comparação da distribuição do rebanho de vacas ordenhadas com a distribuição do leite produzido nas chamadas mesorregiões maranhenses.

Observa-se, pelo Gráfico 02 que enquanto regiões como o Oeste contribuem para a elevação da produtividade do rebanho estadual, pois o mesmo detém $49 \%$ do rebanho e 59\% da produção, regiões como o Centro contribuem para a redução da mesma, uma vez que a mesma detém $24 \%$ do rebanho e apenas $20 \%$ da produção. Entretanto, em se tratando das características produtivas do Sul maranhense, pode-se observar que se trata do produtor típico do estado, uma vez que rebanho ordenhado e a produção de leite podem ser representados exatamente pelo mesmo número (12\%).

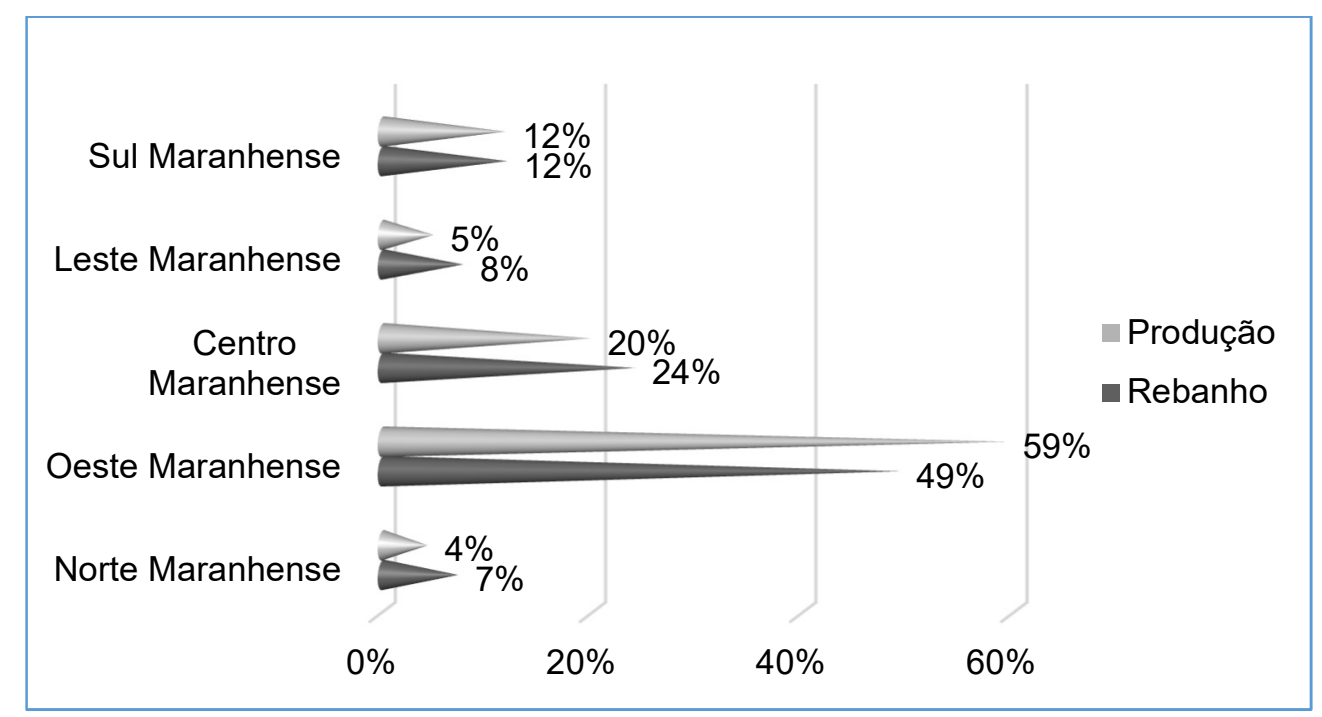

Gráfico 02: Participação das mesorregiões do Maranhão no setor (\% em 2015).

Fonte: IBGE (Banco de dados SIDRA).

Isto indica que é exatamente nesta região que está concentrado o produtor de leite típico do Maranhão, que não influi sobre a produtividade média estadual; nem de forma positiva e nem de forma negativa. Isto implica que as características da produção leiteira maranhense podem ser bem refletidas por aquelas características que prevalecem na mesorregião em tela, a saber: produção em pequena escala; rebanho predominantemente mestiço (não selecionado); ordenha manual; inseminação natural; baixa incidência de equipamentos nas propriedades (MOREIRA, 2016).

Em regiões com padrões de baixa eficiência naturalmente se espera encontrar algo como uma baixa adesão a normas como aquelas que são exigidas pelo Ministério da Agricultura. Para uma primeira comprovação deste cenário, o Gráfico 03 apresenta a situação dos produtores em relação à adaptação à INNNo 62.

Considerando que já foi vencido o prazo de adaptação anteriormente estabelecido pela IN № 51, e em plena iminência de vencimento dos prazos da IN № 62, os dados disponíveis no Gráfico 03 mostram que ao final do ano de 2015 apenas 19\% das 
p. 9 - Pequena produção leiteira no sul do Maranhão: Instruções normativas oficiais e adequação dos produtores

propriedades estavam plenamente adaptadas, somando-se ao fato de que, àquela altura, $35 \%$ dos entrevistados ainda desconheciam a referida norma. Pode-se concluir, portanto, que a tendência é que haja, em um futuro próximo, uma segregação de grande parte da produção regional de leite a mercados marginais, como a venda porta a porta, ou a mercados informais como pequenos comércios informais que utilizam o leite como insumo para o preparo de produtos como lanches e refeições.

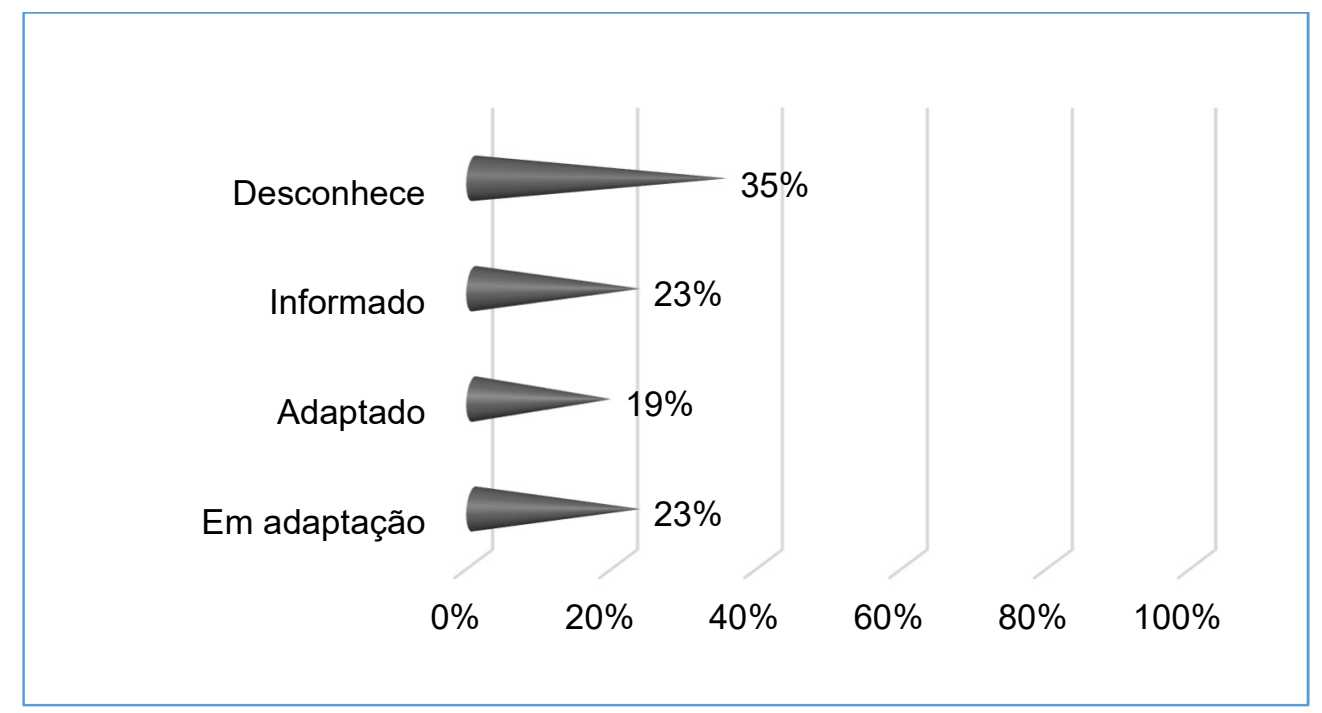

Gráfico 03: Situação dos produtores de leite em relação à IN-62 (Ano 2015).

Fonte: Cálculos om base em dados fornecidos pelo SEBRAE (2016).

Portanto, o cenário descrito acima apresenta uma configuração desalentadora, tendo em vista a morosidade e o nível de desinformação quanto ao processo de adaptação aos padrões normativos vigentes, como é o caso da IN № 62. Mesmo que seja acrescido ao grupo dos produtores que já concluíram o ajustamento (19\%) o grupo dos produtores que informaram que estão em processo de amoldamento (23\%),mesmo assim a atividade leiteira da microrregião de Imperatriz ainda estaria bastante vulnerável em termos de capacidade de atuar como fornecedora em mercados organizados (indústria/laticínios), uma vez que estes mercados costumam pressupor a observância de normas como aquela que constitui o foco do presente trabalho, pois, eles mesmos são obrigados a cumprir alguns preceitos emanados de tais instrumentos normativos.

\section{METODOLOGIA E RESULTADOS}

No final do ano de 2015 foi realizada uma pesquisa de campo envolvendo a participação de 149 produtores de leite da região Sul do Maranhão, enfatizando a microrregião de Imperatriz. A pesquisa fez parte do plano de trabalho de um convênio entre a Universidade Federal do Maranhão e o SEBRAE-MA, que previa várias outras iniciativas do mesmo gênero, abrangendo sempre empreendimentos de micro e pequeno porte, uma vez que o referido órgão de apoio oferece um portfolio de serviços 
a negócios dessa dimensão, incluindo consultorias, palestras, cursos, divulgação de material informativo, participação em feitas e eventos, dentre outros. No caso específico da pesquisa de campo com os produtores de leite, o questionário aplicado abordava os mais diferentes aspectos das propriedades leiteiras, constando inclusive algumas questões sobre o tema da adaptação dos produtores à IN 62 do Ministério da Agricultura.

\subsection{Aspectos metodológicos}

No caso das perguntas sobre a adaptação dos produtores, inseridas no questionário aplicado, tem-se uma particularidade que chama atenção, que é o fato da variável examinada não se enquadrar em um dos principais requisitos dos modelos normalmente tratados pelos economistas, qual seja: o fato da mesma não se apresentar como uma variável aleatória e contínua. Ao contrário, no caso atual, o que se verifica é a existência de meros atributos, indicando uma espécie de sim ou não, externando o fato dos produtores entrevistados estarem ou não adaptados à Instrução Normativa 62. Portanto, também não pode ser dito nem mesmo que se trata da uma variável discreta, no seu significado mais estrito, visto que somente duas possibilidades podem ser evidenciadas em cada resposta, a saber: adaptado ou não adaptado. Por fim, não se trata nem mesmo de um fenômeno que a princípio se manifeste por meio de números, mas, como já referido, o mesmo se manifesta por meio da afirmação ou negação daquele atributo.

Em casos como este os pesquisadores costumam transformar os atributos da variável dependente em números arbitrários, viabilizando assim uma transformação de algo que se expressa de maneira qualitativa em algo que se expressa de maneira quantitativa (numérica). No presente caso, seguir este procedimento corresponderia a atribuir o valor 1 (um) para os casos de produtores que se encontram adaptados à IN № 62 e atribuir o valor 0 (zero) para os casos de produtores que não se encontram adaptados. Ou seja, partindo de um mero atributo, tem-se agora uma variável binária que assume os valores 0 ou 1.

Quando se confronta, em termos econométricos, uma variável binária (conforme especificado acima) com um conjunto de variáveis independentes, que possivelmente influenciam os atributos da mesma, se obtém como resultado a probabilidade de ocorrência de cada um dos desses atributos. Mas antes da adoção de um recurso econométrico, convém especificar um conjunto de variáveis que se candidatariam a constar no rol das chamadas variáveis independentes (explicativas) no caso em tela.

É certo que fatores não apenas de natureza econômica podem causar influência sobre o fenômeno em estudo. Fatores culturais e sociológicos podem também exercer um papel importante. Contudo, a pretensão aqui não é esgotar a lista das variáveis explicativas, mas, tão somente, testar a pertinência de algumas delas, de forma que, de algum modo, estejam presentes por conta de uma convincente justificativa econômica para tal. Outro critério também considerado é que, por meio da pesquisa de campo realizada com os produtores, seja possível ter acesso a dados que possam representá-las. 
p. 11 - Pequena produção leiteira no sul do Maranhão: Instruções normativas oficiais e adequação dos produtores

Trata-se, pois, da tarefa de elencar um conjunto de fatores (F) que teoricamente influenciariam os produtores nas suas decisões de se adaptarem ou não aos instrumentos normativos oficiais que regulamentam a produção de leite. Tal conjunto de fatores aparecerá aqui representado por variáveis como: o tipo de mercado para o qual o produtor fornece o seu produto, os métodos que os produtores costumam empregar, o contato do produtor com alguma espécie de orientação, o acesso à informação (meios de comunicação), o tamanho do empreendimento e, por fim, o fato do produtor manter vínculos com entidades de classe.

O referido conjunto de fatores (F) passa a ser representado por uma função que tenta captar a presença das variáveis acima elencadas. De modo mais específico:

$$
F=f(m, t, o, i, r, s) \quad(\text { Eq. } 01)
$$

Onde:

$m$ = Percentual da produção destinado à indústria / laticínios

$\mathrm{t}=$ Utilização do método de inseminação artificial

$\mathrm{o}=$ Recebimento de orientação e/ou materiais informativos sobre a produção de leite

$\mathrm{i}=$ Acesso à internet

$r=$ Tamanho do rebanho leiteiro

s = Vínculo com associações ou cooperativas de produtores

Os argumentos econômicos que associariam as variáveis explicativas escolhidas ao fenômeno em análise poderiam ser mais explicitamente compreendidos nos seguintes termos:

a) Percentual da produção destinado à indústria / laticínios: espera-se que os produtores que abastecem indústrias / laticínios tendem a promover um maior esforço de adaptação aos padrões normativos, em vista das próprias exigências que este tipo de comprador tende a impor aos seus fornecedores;

b) Utilização do método de inseminação artificial: como não se trata de algo obrigatório do ponto de vista das normas oficiais, espera-se que os produtores que utilizam técnicas avançadas como esta estejam mais propensos a se adaptar a normas regulamentares, tendo em vista que, espontaneamente, já demonstram estar em busca dos melhores métodos e padrões (modernização);

c) Recebimento de orientação e/ou materiais informativos: neste caso torna-se apropriado esperar que aqueles produtores que receberam orientações de órgãos de apoio, de forma direta ou por meio de materiais informativos 
Cesar A. L. Lemos de Freitas; João G. de Moura e Ricardo Z. Affonso de Paula - p.12

(publicações), terão maior propensão para se adequar às exigências dos órgãos oficiais;

d) Acesso à internet: esta variável foi introduzida no modelo como sendo uma forma de captar o nível de acesso à informação. Espera-se que aqueles produtores mais informados e, portanto, mais sintonizados com o mundo à sua volta, tendem a compreender melhor as exigências impostas e a oferecer um menor nível de resistência a exigências como aquelas contidas na IN № 62 ;

e) Tamanho do rebanho leiteiro: imagina-se, a priori, que grandes empreendimentos se adaptam com maior facilidade às exigências legais. Por dispor de uma maior escala de produção os maiores empreendimentos acessariam mais facilmente os recursos necessários para colocar em prática os padrões exigidos.

f) Vínculos com associações / cooperativas: no caso desta variável é plausível esperar que os produtores que se encontram vinculados a entidades de classe tenham uma maior propensão a se adequar a instrumentos normativos, tendo em vista diversos motivos: maior facilidade de acesso à assistência técnica, maior sintonia com o mercado, maior facilidade de acompanhamento dos padrões adotados pelos demais integrantes da entidade, etc.

Neste sentido, por se tratar de um modelo cuja variável dependente possui a particularidade de ser uma variável binária, fica afastada, de imediato, a utilização de técnicas tradicionais como a análise de regressão múltipla. São basicamente dois fatores impeditivos neste contexto, quais sejam: a exigência de uma variável independente contínua e a exigência de linearidade na relação entre a variável dependente e as variáveis independentes (STOCK e WATSON, 2004).

O fato de não se tratar de uma variável dependente contínua já ficou evidenciado anteriormente, ensejando que a função a ser especificada mostrará, na verdade, a probabilidade dos produtores possuírem ou não um determinado atributo (adaptação à IN № 62), o que de imediato passaria a requerer a utilização de uma técnica alternativa como o modelo de probabilidade linear. O problema é que o uso deste último recurso termina por gerar resultados pouco aceitáveis em certos casos, tendo em vista que nem sempre as probabilidades calculadas obedecem à regra de se situarem entre zero e um. A presença de algo assim levaria a uma dificuldade de interpretação adequada dos resultados, neste caso, em razão da admissão da linearidade nas relações.

Para fugir de amarras dessa natureza, existem regressões conhecidas como Probit e Logit, que são largamente utilizadas nos modelos cujas variáveis independentes são binárias, assegurando algumas vantagens que the são peculiares. As diferenças nos resultados gerados pela escolha de uma dessas duas abordagens (métodos) são marginais, ou de quase nenhuma significância. Mesmo assim existe uma visível predileção dos pesquisadores pelo uso das funções do tipo Logit, sobretudo pela maior 
p. 13 - Pequena produção leiteira no sul do Maranhão: Instruções normativas oficiais e adequação dos produtores

facilidade de compreensão da natureza analítica da função e dos próprios procedimentos de cálculo (STOCK e WATSON, 2004; ALDRICH e NELSON, 1984).

Diante do exposto, no presente caso faz-se a opção pela adoção de uma regressão do tipo Logit, que pode ser especificada nos seguintes termos:

$$
\operatorname{Pr}(\text { adaptação })=\frac{\exp \left(\alpha F_{t}\right)}{\left[1+\exp \left(\alpha F_{t}\right)\right]}
$$

Onde:

exp $=$ o número $e$, que corresponde à base do logaritmo natural

$F=$ matriz composta pelas variáveis independentes apresentadas na equação 01

$\alpha=$ coeficientes representativos das variáveis independentes.

As principais vantagens decorrentes do uso de uma especificação do tipo Logit podem ser resumidas nos seguintes termos: i) tem-se a garantia de que os valores das probabilidades se situam sempre no intervalo entre zero e um, dispensando restrições de qualquer natureza sobre os valores que os coeficientes estimados nas regressões devem assumir; ii) tal especificação não necessita da suposição de efeitos marginais constantes para qualquer valor inicial de uma variável independente. Portanto, além do sinal dos coeficientes estimados se mostrarem corretos, também a própria relação entre as variáveis obtidas nas estimativas se aproximarão da verdadeira relação existente entre as mesmas, em toda extensão da amostra, e não apenas numa faixa singular da mesma, como seria o caso diante de circunstâncias em que fossem admitidas hipóteses mais restritivas, como é o caso da hipótese da linearidade (ALDRICH e NELSON, 1984).

Deste modo, tendo em vista o uso bastante difundido da especificação Logit em estudos dessa natureza e os argumentos acima apresentados, acredita-se que a utilização da mesma na ocasião presente pode ser considerada como oportuna e apropriada.

\subsection{Resultados e discussão}

Embora tenha sido anunciado anteriormente que a pesquisa de campo abrangeu uma amostra de 149 produtores de leite, a partir de um universo composto por 228 empreendimentos leiteiros assistidos na região pelo SEBRAE-MA, para efeito das estimativas aqui apresentadas considerou-se apenas os dados captados junto a 144 entrevistados. O descarte de 5 questionários se deveu ao fato dos entrevistados terem omitido informações referentes a pelo menos uma das variáveis essenciais.

Os resultados das estimativas geradas a partir da aplicação da metodologia sugerida estão expostos na Tabela 01. 
Cesar A. L. Lemos de Freitas; João G. de Moura e Ricardo Z. Affonso de Paula - p.14

Tabela 01: Determinantes da adaptação dos produtores à IN № 62

\begin{tabular}{cccc}
\hline Variável & Coeficiente & Erro padrão & z \\
\hline Constante & $-3,2082$ & 0,6394 & $-5,018$ \\
M & 1,4411 & 0,6004 & 2,4 \\
T & 1,1888 & 0,5915 & 2,01 \\
O & 1,1686 & 0,4826 & 2,422 \\
I & 0,0777 & 0,6832 & 0,114 \\
R & 0,0006 & 0,0055 & 0,114 \\
S & 0,3361 & 0,4715 & 0,713 \\
\hline
\end{tabular}

Fonte: Cálculos om base em dados fornecidos pelo SEBRAE (2016).

Antes de iniciar a análise direta dos dados que constam na Tabela 01 convém esclarecer três pontos importantes sobre a interpretação de resultados decorrentes da aplicação de modelos binários. O primeiro ponto é que os coeficientes estimados, em termos de seus próprios valores, não possuem um significado preciso, fazendo com que toda a atenção se volte para o seu sinal, isto é, a direção da influência de cada variável. O segundo ponto é que o tradicional coeficiente de determinação $\left(R^{2}\right)$ da análise de regressão também não se aplica ao caso desses modelos, gerando apenas um indicador que se aproximaria do mesmo em termos de interpretação, sendo costumeiramente denominado Pseudo- $R^{2}$. Finalmente, o terceiro ponto tem apenas a finalidade de esclarecer que a estatística z, disponível na Tabela 01, exerce uma função semelhante àquela exercida pela estatística t nos modelos tradicionais.

As estimativas apresentadas na Tabela 01 mostram inicialmente que os sinais dos coeficientes das variáveis dependentes se mostram sempre positivos, conforme seria esperado a priori. O sinal negativo da constante e o seu nível de significância têm pouco a revelar neste caso, motivo pelo qual este parâmetro específico será excluído das considerações a serem manifestadas neste trabalho.

Mas o dado inicial que merece atenção, de fato, é que, para além do sentido da influência, expressado pelo sinal dos coeficientes, observa-se que os parâmetros estimados para as três primeiras variáveis são significativos (ao nível de 5\%), ao passo que para as três últimas variáveis não o são. Ou seja, as variáveis que representam o tipo de mercado para o qual o leite se destina $(\mathrm{m})$, os métodos empregados na propriedade (t) e o fato de receber orientação direta ou impressa sobre o produto (o) foram fatores que contribuíram significativamente para que os produtores da região se adaptassem aos padrões normativos oficiais destinados à atividade leiteira.

Enquanto isso, embora o sinal dos coeficientes das demais variáveis indique uma relação no sentido esperado, fatores como o acesso à internet (i), o tamanho do rebanho leiteiro ( $r$ ) e a manutenção de vínculos com associações ou cooperativas (s) não se mostraram capazes de exercer influência considerável sobre a adaptação dos produtores 
p. 15 - Pequena produção leiteira no sul do Maranhão: Instruções normativas oficiais e adequação dos produtores

à IN № 62. Em síntese, no caso das três últimas variáveis, não há indícios de que haja uma influição que chegue a aumentar de forma considerável a probabilidade de um produtor qualquer tomar as medidas necessárias para inserir-se no grupo daqueles que atendem aos padrões ditados pela Instrução Normativa 62 do Ministério da Agricultura.

Quanto à variável representativa do mercado que o produtor atende, representada aqui pela fração da produção que é destinada à indústria/laticínios, de acordo comas estimativas disponíveis na Tabela 01, o fato da mesma se mostrar significativa pode ser expressa no seguinte contexto: quanto maior a parcela do leite produzido numa propriedade que tenha como destino a indústria/laticínios (mercados organizados), maior será a probabilidade deque aquela propriedade esteja adaptada aos padrões normativos. Tais compradores tendem a exigir naturalmente dos seus fornecedores o atendimento das normas em curso, uma vez que os mesmos também estão inseridos no contexto geral de tais normas, não podendo cumpri-las dentro de um contexto isolado.

Do mesmo modo, quando uma propriedade utiliza métodos mais modernos de manejo do rebanho, que nem mesmo constituem uma exigência legal, como é o caso aqui da inseminação artificial, naturalmente, isto já seria um demonstrativo da inclinação desta unidade produtiva para a utilização de técnicas e padrões mais modernos e rígidos, tornando-os menos avessos ao cumprimento de uma exigência oficial nesse sentido. Como o coeficiente apresenta o sinal esperado e um elevado nível de significância, isto indica, por si mesmo, que a probabilidade de se tratar de uma propriedade adaptada à IN № 62 aumenta de forma representativa em estabelecimentos com este perfil.

O mesmo acontece com o produtor que recebeu orientações técnicas sobre a produção de leite e materiais impressos (informativos) sobre a atividade. É perfeitamente plausível que estes se inclinem mais facilmente a produzir segundo as normas oficiais, tendo em vista que já se tornaram mais conscientes das restrições que podem sofrer em caso de não se adequarem aos padrões vigentes. O grupo que procura este tipo de orientação tende a ser aquele que se preocupa em permanecer na atividade. Talvez, em vista de tais considerações, seja possível afirmar que tal atitude manifeste a presença deum perfil empreendedor, onde a atividade é encarada como um negócio, com vistas à obtenção de resultados econômicos. Daí então resultaria a significância do parâmetro estimado para este grupo de produtores de leite, mostrando que, quando se trata de pecuaristas portadores da característica de buscar orientação e informação, a probabilidade de se tratar de alguém adaptado ao ambiente normativo tende a ser mais elevada.

Retornando às variáveis que não apresentaram coeficientes significativos, embora apresentando os sinais esperados, no caso do acesso à internet, o mesmo abre muitas possibilidades em relação ao campo das informações, mas que, muitas vezes, o acesso não está diretamente ligado à atividade do produtor e nem mesmo significa o acesso direto e específico a uma exigência como aquela que aqui está posta. O associativismo também poderia contribuir para os propósitos focalizados neste estudo. Entretanto, entidades como associações e cooperativas talvez tenham contribuído, e se tornado mais proveitosas em outros campos, tais como: aquisição de insumos a preços mais acessíveis, obtenção de melhores preços pelo produto na comercialização, 
facilitação no acesso ao crédito, etc.; e não exatamente como elemento impulsionador da decisão do produtor para adaptação às normas previstas pelo Ministério da Agricultura, pelo menos quando se trata do grupo que compõe a amostra em análise. Por fim, o tamanho do rebanho, embora não deixe de exercer alguma importância como fator representativo da escala de produção, quando se trata dos produtores aqui analisados, este fator pode ter sido suplantado pelo fato de que, mais importante do que a escala, deve ter sido a própria forma como a atividade é gerida, principalmente em termos de a mesma possuir uma função voltada para a obtenção de resultados econômicos (captado pela variável t), a partir de um gerenciamento que prioriza a adoção das melhores práticas (eficiência).

Após a análise acima desenvolvida, convém que sejam feitas algumas conjecturas sobre a capacidade do modelo em explicar o problema proposto. Mais precisamente, tendo em vista que não se dispõe de um coeficiente de determinação $\left(R^{2}\right)$ nos modelos do tipo Logit, sendo possível contar apenas com um Pseudo- $R^{2}$, juntamente com este último indicador será apresentada a seguir a chamada taxa aparente de erro, ou, em sentido oposto, a capacidade de previsão acertada do modelo. Para tanto, os dados se encontram disponibilizados na Tabela 02.

Tabela 02: Taxa aparente de erro

\begin{tabular}{ccc}
\hline & Previsto $=1$ & Previsto $=0$ \\
\hline Amostra $=1$ & 3 & 26 \\
Amostra $=0$ & 1 & 114 \\
\hline
\end{tabular}

Fonte: Cálculos om base em dados fornecidos peloSEBRAE (2016).

Pseudo- $R^{2}=0,14$ (McFadden).

Pelos dados disponibilizados na Tabela 02 é possível observar que, considerando uma amostra efetiva de 144 informações, o modelo previu $117(=3+114)$ casos corretamente e $27(=1+26)$ casos erroneamente. Isto quer dizer que a taxa aparente de erro é de aproximadamente $18,8 \%$ (= 27/144). De outro modo, isto significa em $81,2 \%$ dos casos o modelo estimado prevê corretamente que o produtor é adaptado quando de fato o é, e que o produtor não é adaptado quando de fato não o é. Tendo em vista que deve existir um conjunto de outras variáveis que interferem nas decisões dos produtores de leite quanto à sua adaptação à IN № 62, e que não seria possível esgotar a lista no âmbito deste trabalho (variáveis culturais, sociológicas e econômicas), a capacidade de previsão demonstrada acima revela que, embora com uma lista restrita de variáveis explicativas, algumas das mais relevantes foram aqui incorporadas, considerando que pelo menos três delas demonstraram ser relevantes, entre as seis que foram inicialmente propostas.

Veja-se que o valor do Pseudo- $R^{2}$ de 0,14 parece indicar uma baixa capacidade de explicação do modelo proposto, o que, de certo modo, contrastaria com os resultados extraídos a partir dos dados mostrados na Tabela 02. No entanto, tendo em vista as 
p. 17 - Pequena produção leiteira no sul do Maranhão: Instruções normativas oficiais e adequação dos produtores

limitações presentes na tentativa de obtenção de um possível indicador do que seria o coeficiente de determinação no uso de métodos de estimação do tipo Logit, a análise contida no parágrafo anterior talvez explicite melhor a capacidade conjunta das variáveis destacadas em oferecer respostas ao problema que constitui o foco deste estudo. Ou seja, não se trata da necessidade de esgotar a lista das variáveis explicativas, gerando um alto poder explicativo para a equação especificada. De outro modo, trata-se da oportunidade de encontrar variáveis que participem do rol dos fatores determinantes das decisões dos produtores e, a partir daí, dispor de algumas indicações para a atuação de agentes públicos e privados na reversão da situação vigente entre os pequenos produtores de leite da microrregião de Imperatriz.

No caso, os resultados apresentados no presente trabalho indicam que iniciativas que visem atrelar os pecuaristas aos mercados organizados, aliadas à viabilização de um maior acesso à informação e orientação, parece ser um bom caminho para que os mesmos não venham a ser excluídos da possibilidade de continuar desenvolvendo a sua atividade e comercializando normalmente o seu produto.

\section{CONSIDERAÇÕES FINAIS}

Pelo simples fato do Brasil vir se tornando uma economia mais aberta a partir do início dos anos 1990, e os mercados cada vez mais exigentes com relação ao cumprimento de normas de qualidade e padrões de segurança para os consumidores, os estabelecimentos produtivos, nos mais diferentes ramos de atividade, têm se deparado com a necessidade de enquadramento em normas e padrões que a cada dia se mostram mais exigentes e diversificados.

De longa data a produção de leite no Brasil é regulamentada pelo Ministério da Agricultura, regulamentação esta que culminou com a publicação recente das instruções normativas IN № 51 e IN № 62. O não atendimento aos requisitos previstos nestas normas tende a impedir que os produtores de leite possam ofertar o seu produto em mercados formais (organizados), como é o caso do mercado formado pelos laticínios. Em regiões como o Sul do Maranhão, caracterizada pela presença de empreendimentos que, por razões diversas, não primam pela adoção das melhores práticas, a entrada em vigor da Instrução Normativa № 62 pode impedir até mesmo o simples transporte do produto por rodovias e, principalmente, eliminar qualquer possibilidade de comercialização que não seja para mercados informais, como a venda direta ao consumidor (porta a porta), ou para pequenos estabelecimentos informais que utilizam o leite como ingrediente para o preparo de alguns itens do seu cardápio.

Uma pesquisa recente promovida pelo SEBRAE-MA, que retrata a situação de 149 produtores da referida região maranhense no final do ano de 2015 indica que apenas $19 \%$ dos mesmos estavam, àquela altura, adaptados à IN № 62, enquanto um grupo de 23\% estava em processo de adaptação. Ou seja, somando-se estes dois grupos, não é possível obter nem mesmo a metade do total de entrevistados em vias de atender às exigências da legislação oficial. Mais grave ainda, algo em torno de 35\% das propriedades contidas na amostra demonstrava desconhecer por completo a existência da norma em análise. Daí se concebe um ambiente marcado por uma espécie de dualidade, 
considerando que, enquanto alguns pecuaristas já se ajustaram às exigências oficiais, outros sequer estão cientes da existência de tais exigências.

Diante deste quadro, após o emprego dos recursos metodológicos especificados no escopo deste estudo, constatou-se que a probabilidade de que um produtor de leite estar adaptado às normas vigentes aumenta quando este mantém relações com mercados organizados (laticínios/indústria); quando o mesmo já ostenta uma predisposição para a adoção dos melhores métodos e técnicas (visão empreendedora); e quando o mesmo é exposto a informações que podem ser fornecidas diretamente (orientação técnica) ou por meio de publicações que tratam da produção leiteira. Portanto, o fato de haver uma significativa proporção de propriedades não adaptadas a instrumentos normativos como a IN № 62 demonstra o quanto estes três fatores determinantes estão ausentes do ambiente das unidades produtoras de leite da região Sul do Maranhão.

Sendo assim, as ações a serem deflagradas na região por agentes públicos, órgãos de apoio e entidades de classe (tomando como base os resultados encontrados neste estudo), poderiam ser direcionadas para o estímulo a uma habitualidade empreendedora na região; para a promoção da assistência técnica, prestando orientação e informação ao produtor; e para o fomento à conexão dos produtores a mercados organizados. Pela análise apresentada ao longo do texto, se tornou sugestivo manifestar que iniciativas dessa natureza poderiam induzir um maior contingente de unidades produtoras de leite a se tornarem cumpridoras das normas em vigor, permitindo a sua permanência no mercado e, desse modo, viabilizando a manutenção da ocupação e da renda dos empreendedores da pecuária de leite da microrregião de Imperatriz, no Sul do Maranhão.

\section{REFERÊNCIAS BIBIOGRÁFICAS}

ALDRICH, J. H.; NELSON, F. D. Linear probability, logit and probit models. Newbury Park: SAGE Publications, 1984.

ARÊDES, A; SILVEIRA, S. F. R; LIMA, A. A. T. F. C.; ARÊDES, A. F; PIRES, S. V.. Análise de custos na pecuária leiteira: um estudo de caso das propriedades assistidas pelo Programa de Desenvolvimento da Pecuária Leiteira da Região de Viçosa. Custos e @gronegócio on line - v. 2, n. 1, pp. 45-68 - Jan/Jun - 2006.Disponível em:http://www.custoseagronegocioonline.com.br/numero1v2/Analise\%20de\%20custo s.pdf. (Acesso em dezembro de 2015).

BRASIL. RIISPOA - Regulamento da Inspeção Industrial e Sanitária de Produtos de Origem Animal. Rio de $1952 . \quad$ Daneiro, em:http://www.agricultura.gov.br/arq editor/file/Aniamal/Mercadolnterno/Requisitos/ Regulamentolnspecaolndustrial.pdf. (Acesso em dezembro de 2015).

Portaria no 146 de 07 de março de 1996. Brasília:Ministério da Agricultura,
$\begin{aligned} & \text { Pecuária } \\ & \text { em:http://www.sfdk.com.br/imagens/lei/MA\%20-\%20Portaria\%20146.htm. (Acesso em }\end{aligned}$
dezembro de 2015).


p. 19 - Pequena produção leiteira no sul do Maranhão: Instruções normativas oficiais e adequação dos produtores

- Ministério da Agricultura, Pecuária e do Abastecimento. Instrução Normativa № 51, de 18 de Setembro de 2002. Rio de Janeiro, 2002. Disponível em: www.qualidadedoleite.com.br/hd/.../IN51de2002_leitebnormas.pdf

Instrução Normativa № 62, de 29 de Dezembro de 2011. Brasília: Ministério da

Agricultura, Pecuária e do Abastecimento, 2011. Disponível em:http://central3.to.gov.br/arquivo/174314/. (Acesso em dezembro de 2015).

FAGUNDES, M. H.Uma nova etapa da Instrução Normativa no 51: a região Centro - Sul. 2005.

Disponível

em:http://www.conab.gov.br/OlalaCMS/uploads/arquivos/916a585072c9e47171c3a8a

7454befd6.pdf. (Acesso em dezembro de 2015).

IBGE - Instituto Brasileiro de Geografia e Estatística -Abate de animais, produção de leite, couro ovos. (site, 2015). Disponível em: http://ibge.gov.br/home/estatistica/indicadores/agropecuaria/producaoagropecuaria/d efault.shtm. (Acesso em dezembro de 2015).

MAIA, G. B. S.; PINTO, Rezende, A.; MARQUES, C. Y. T.; ROITMAN, F. B.; LYRA, D. D. Produção leiteira no Brasil. BNDES SetorialV. 37, p. 371-398. Rio de Janeiro, 2013.

MEIRELES, A. J. A (des)razão laticinista: a indústria de laticínios no último quartel do século XX. São Paulo: Cultura, 1996.

MOREIRA, T. C. Perfil da bacia leiteira na região Tocantina - Maranhão. UFMA: São Luís, 2016 (Monografia de Graduação).

RESENDE, J. R. Custo de produção da atividade leiteira: um estudo de caso na região de Gurinhatã - $\quad$ MG. Lavras-MG, $2006 . \quad$ Disponível em:www.consupec.com.br/enviados/200675155314.pdf(Acesso em dezembro de 2015).

SEBRAE - Serviço Brasileiro de Apoio às Micro e Pequenas Empresas -. Diagnóstico da Cadeia Produtiva do Leite e Derivados - Desenvolvimento da Bacia Leiteira da Região Tocantina e Médio Mearim. São Luís - MA, 2003. Disponível em: 201.2.114.147/bds/bds.nsf/.../\$File/NT0009EF92.pdf (Acesso em dezembro de 2015).

2016.

Agronegócio do Leite e Derivados na Região Sul - Fase T2. SEBRAE-MA: São Luís,

SOCK, J. H.; WATSON, M.W. Econometria. São Paulo: Addison Wesley, 2004.

VIDOR, A. C. M.; Alterações na Legislação Higiênico-Sanitária do Leite Fluido: uma analise da legislação brasileira frente às legislações internacionais. Porto Alegre, 2002. Disponível em:http://www.lume.ufrgs.br/handle/10183/4602 (Acesso em dezembro de 2015).

WILKINSON, J. Estudo da Competitividade da Indústria Brasileira: Competitividade da Indústria de Laticínios. Campinas: FEC, 1993. 